\title{
Wildlife v. the Bulldozer in
}

\section{Tasmania}

\author{
By Eric Guiler
}

Pressures on wild land, especially forest, are as great in Tasmania as elsewhere, but the Government has given the conservationists splendid support, and one-sixth of the entire country, in the form of reserves, sanctuaries and other protected areas, is now controlled by the Animals and Birds Protection Board, of which Dr. Guiler is Chairman. Nevertheless pressures are increasing, especially on the vitally important sclerophyll forest, and the task now, says Dr. Guiler, is to persuade the people to tolerate wildlife outside the reserves, and especially to persuade farmers to leave pockets of scrub and forest on their land. But scrub that shelters desirable species also harbours the nuisance ones, and it is not easy to persuade a farmer that he likes wallabies.

\begin{abstract}
TASMANIA is a small state of approximately 26,000 square miles, the eastern part, generally speaking, being very hilly and the western half very rugged. In conservation matters Tasmania's greatest advantage lies perhaps in its recent human occupation which dates only from 1801; the great population pressures which we find in many, if not most, other countries of the world do not occur there. The alienation of the countryside is only beginning to show, and much of our land is still available for reservation.
\end{abstract}

The rainfall clearly influences Tasmania's vegetational pattern. The map on page 99 shows the large area covered by sclerophyll forest, and also illustrates the spread of the clearance programmes from the low-lying midland areas into these forests. In the western mountainous regions there are large areas of rain forest. Much of the midland development took place before 1884; from then until 1914 more distant parts were developed. A more alarming recent trend has been a general destruction of forest areas on the fringes of agricultural land. The era of the bulldozer has reached us, and clearance is no longer a matter of muscles but of dieselene. Indeed, a sociological factor also operates here, since land development is often undertaken as a write-off against income tax, and some land is being cleared for this purpose.

The vegetation map shows clearly that the agricultural development is taking place at the expense of sclerophyll forest. This forest ranges from open savanna woodland to dense stands of timber, the species of both the understorey and the forest varying with the rainfall, aspect and geographical location. This type of forest supports much of our wildlife. The Tasmanian marsupial fauna is not as rich and diversified as that of continental Australia, but it is unique as being 


\section{Table 1: Habitats of the larger Tasmanian marsupials}

\begin{tabular}{|c|c|c|}
\hline Macropus giganteus & Forester kangaroo & Open sclerophyll forest \\
\hline Wallabia rufogrisea & Bennett's wallaby & Sclerophyll forest, scrub \\
\hline Thylogale billardieri & Pademelon & Scrub, low forest \\
\hline Bettongia cuniculus & Bettong & Open forest, forest fringe \\
\hline Potorous tridactylus & Potoroo & Scrub \\
\hline Isoodon obesulus & Bandicoot & Scrub \\
\hline Perameles gunni & Barred bandicoot & Open plains \\
\hline Vombatus ursinus & Wombat & $\begin{array}{l}\text { Heath, scrub, sclerophyll } \\
\text { forest }\end{array}$ \\
\hline Trichosurus vulpecula & Brush possum & $\begin{array}{l}\text { Sclerophyll fores t, } \\
\text { forests }\end{array}$ \\
\hline Pseudochirus convolutor & Ringtail possum & Forests generally \\
\hline Dasyurus quoll & Native cat & Scrub, sclerophyll forest \\
\hline Dasyurus maculatus & Tiger cat & $\begin{array}{l}\text { Forests generally, re- } \\
\text { stricted range }\end{array}$ \\
\hline Thylacinus cynocephalus & Thylacine & $\begin{array}{l}\text { Sclerophyll forests, } \\
\text { sedgeland }\end{array}$ \\
\hline Sarcophilus harrisi & Tasmanian devil & $\begin{array}{l}\text { Forests generally, sedge- } \\
\text { land, heath }\end{array}$ \\
\hline
\end{tabular}

the last stronghold of the large carnivorous marsupials, the thylacine and the Tasmanian devil. In addition, many of the small grounddwelling species, such as the bandicoots and dasyures, abound in the absence of dingoes and foxes. One of the features of the largest species is the wide range of microhabitats which they inhabit. Table 1 shows these for the large species. There is an interesting parallel in the distribution of the potoroo Potorous tridactylus and the bettong Bettongia cuniculus on the one hand, and the thylogale Thylogale billardieri and the wallaby Wallabia rufogrisea on the other hand. The smaller of these species, the potoroo and the thylogale, live in the denser scrub, while the wallaby and the bettong live in the more open forest.

The dependence of all these species upon the sclerophyll forest is very evident, and the same picture holds true for our birds. The 222 species of birds in Tasmania include only a small number of endemic species, but a large number of endemic sub-species. Of the total, 91 species are marine, and 33 are non-forest dwellers, including some aquatics; but no fewer than 66 of our 132 terrestrial species are dependent upon forests or scrub for their habitat, and of the remaining 66 species a further 32 use sclerophyll scrub together with another habitat for their existence. Thus, 98 of our bird species are dependent entirely, or in part, upon sclerophyll forest and its associated scrub.

Forest clearance is not the only impact that man has on the forests since much of these lands are used as rough grazing for cattle and sheep. Fires are an ever present threat, but recent evidence shows that our fauna has a high fire tolerance.

It is apparent that our greatest agricultural pressure is exerted on 


\section{Vegetation map of Tasmania}

Note that the impact of clearing is largely upon the sclerophyll forest

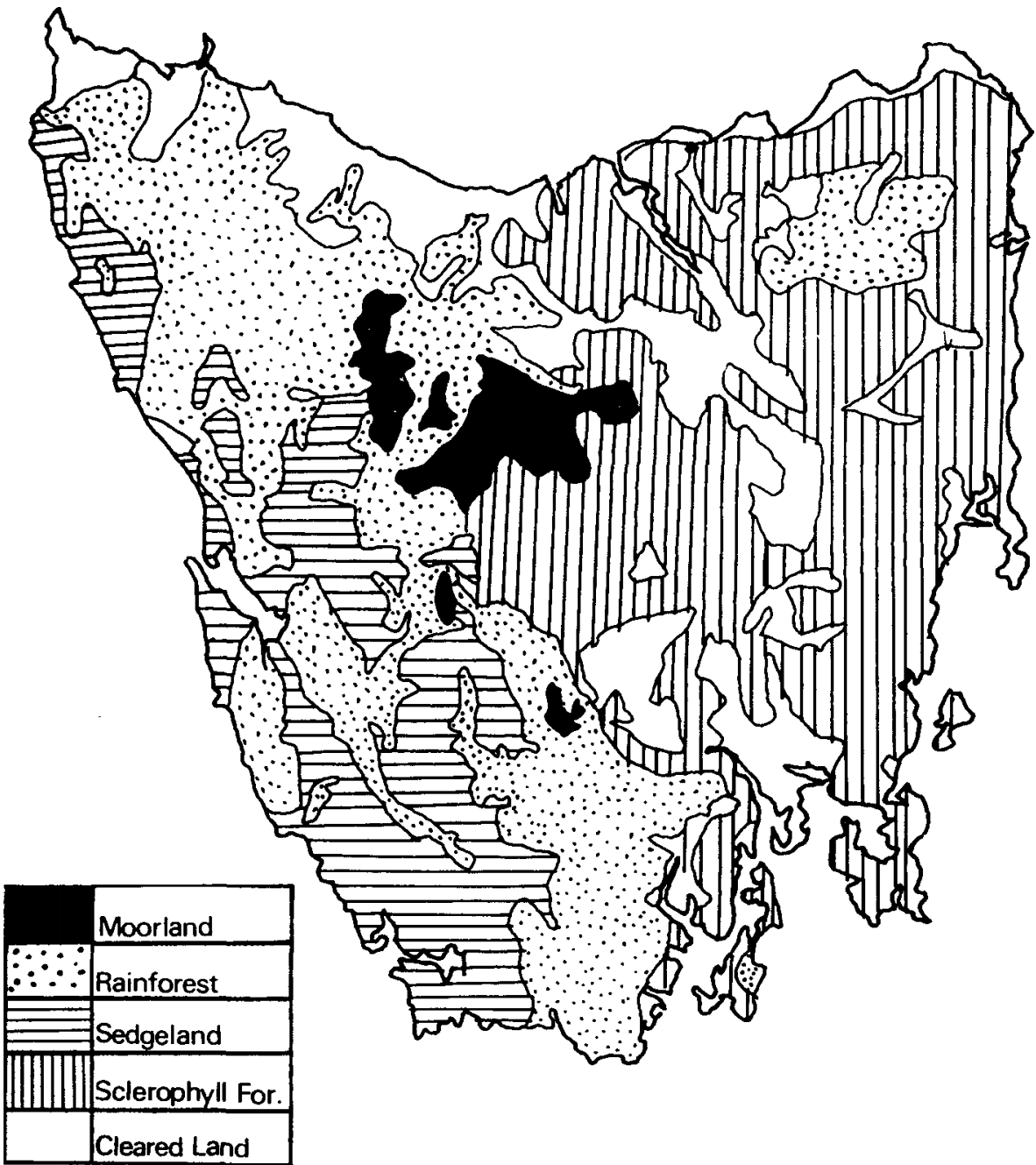

the very habitat which supports our greatest number of both species and individuals, and, above all, our greatest treasures. Destruction of this habitat undoubtedly contributed to the decline of the thylacine, and the pressure on it will increase in the future. Tasmania is not alone in this; throughout Australia large areas of scrub and forest are being cleared. It is absolutely essential that the sclerophyll habitat be conserved, and this could lead to a major clash between wildlife and agricultural interests. Fortunately the forest trees are valuable for logging, and this helps, but the development of Pinus plantations lea.ds_to a barren wildlife area. The decla ration of sanctuaries, game 
and habitat reserves has been carnied almost to the limit of our expectations and reflects the government's sympathy with our aims. We are proud of the fact that approximately one-sixth of Tasmania is under the control of our Animals and Birds Protection Board. Sclerophyll forest and open savanna woodland do not figure as largely as we would like in this system, but we recently acquired a reserve of $1,600,000$ acres which includes forests. Another sanctuary of 50,000 acres is exclusively sclerophyll forest, and probably another 150,000 acres of sclerophyll is reserved in different sanctuaries.

We are helped by the present economic trends of farming. Island farms are not a paying proposition, and negotiations are actively under way for the purchase of a 23,000acre sclerophyll island, Maria Island, for development as a faunal reserve where the fauna may be seen by visitors. In this connection, the force of controlled tourism as a selling point for fauna projects cannot be ignored.

We hope to avoid the wildlife barrens of open fields, and by education and drive have more shelter belts. We are at the stage where we must move out of our reserves and sanctuaries and ensure that pockets of forest and scrub are left on developing farmland. But caution is necessary since scrub means rabbits and even wallabies, and these are in the category of nuisance species. We badly need a reserve in the north-east savanna woodland for the forester kangaroo Macropus giganteus, and this matter is being energetically pressed at the present moment.

The same pressures that threaten our land fauna are also encroaching on our waterfowl resources. We are creating habitat reserves on critical waterways to prevent their elimination by drainage, and resting sites on flight paths are also getting attention.

Not all agriculture is deleterious to wildlife. The clearance of forest and savanna woodland results in more habitat for open-country species such as the barred bandicoot Perameles gunni, and for forest fringe species. The clearance of islands in the Furneaux Group has resulted in a great deal of new habitat for the Cape Barren goose Cereopsis novae-hollandiae, and whereas this species in 1890 bred successfully on only three or four islands it now breeds on most of the islands of the group. Only one species, the Tasmanian emu, has become extinct since white settlement, and this occurred over a hundred years ago.

In Tasmania we are not desperately trying to save what is left of the wreckage of our fauna; it is still intact. But continuous vigilance is necessary to ensure that our reserves are not reduced. Increasing :pressures will be felt and our large reserves are our insurance policy against faunal decimation. But even greater insurance can be taken out by encouraging faunal organisations, and other interests, in getting our fauna established outside our reserves without any antagonism from the community at large. This is one of our objects today. 